\title{
Mutactimycin E, a New Anthracycline Antibiotic with Gram-positive Activity
}

\author{
D. Craig Hopp, John Rabenstein, Joshua Rhea, Chris Smith, Khadidja Romari, \\ Midori Clarke, Linda Francis, Macarena Irigoyen, Dennis Milanowski, Michele Luche, \\ Grant J. Carr, Ulla Mocek
}

Received: July 15, 2008 / Accepted: October 16, 2008

(C) Japan Antibiotics Research Association

\begin{abstract}
Resistance to currently available antibiotics has become a widely recognized crisis in the medical community. To address this, many companies and researchers are refocusing their attention towards natural products, which have an excellent track record of producing effective antibacterial drugs. The AMRI natural product library was screened for activity against multi-drug resistant Staphylococcus aureus (MDRSA). The active samples were counter screened for cytotoxicity against the human hepatocellular carcinoma HepG2 cell line to determine an in vitro therapeutic index (in vitro TI). Those samples with a high in vitro TI were selected for fractionation and dereplication. This led to the discovery of a new anthracycline structure. This metabolite, named mutactimycin E (1), exhibited moderate activity against several gram positive organisms. Here we report the isolation, structure elucidation and biological activities of this new compound.
\end{abstract}

Keywords mutactimycin, anthracycline, antibiotic, Amycolatopsis

It has been known for some time that resistance to existing antibiotics is increasing. This is particularly true in hospital settings, but is also found in community-acquired

U. Mocek (Corresponding author), D. C. Hopp, J. Rabenstein, J. Rhea, C. Smith, K. Romari, M. Clarke, L. Francis, M. Irigoyen, D. Milanowski, M. Luche, G. J. Carr: AMRI, Bothell Research Center, 18804 North Creek Parkway, Bothell, WA 98011, USA, E-mail: ulla.mocek@amriglobal.com infections. This development, when coupled with the decision by many pharmaceutical companies to abandon antibacterial research in the 1980's and 1990's, resulted in the absence of new antibiotics to combat current resistance mechanisms. In an effort to address this urgent need, we began a screening campaign to identify novel antibiotics from our natural product library. Natural products, particularly those produced by microbial fermentation, were the direct source or inspiration for almost all antibiotics used today and remain the richest source for new antibacterial compound series. Our extensive library consisting of over 280,000 samples was screened for activity against a multi-drug resistant strain of Staphylococcus aureus (ATCC 43300). The hits arising out of this assay were then tested against the human hepatocellular carcinoma cell line HepG2 to filter out those samples where activity was the result of general cytotoxicity. The resulting subset of samples possessing selectivity for the bacterial target were then fractionated on an HPLC system employing UV, evaporative light scattering, and MS detectors. The eluted fractions were collected into 96-well microtiter plates and submitted for bioassay. Active compounds were subsequently dereplicated on the basis of MS and UV data.

One of the hits resulting from our efforts originated from the EtOAc extract of Amycolatopsis strain 17128. A scaledup fermentation of the active strain and subsequent purification of the active compound by reverse phase HPLC yielded mutactimycin E (1) as an orange solid (Fig. 1). LC/MS data for 1 indicated a molecular weight of 560 Daltons. This piece of information along with the UV spectrum was used to search internal and external databases [1]. Analysis of the hits from this search indicated 


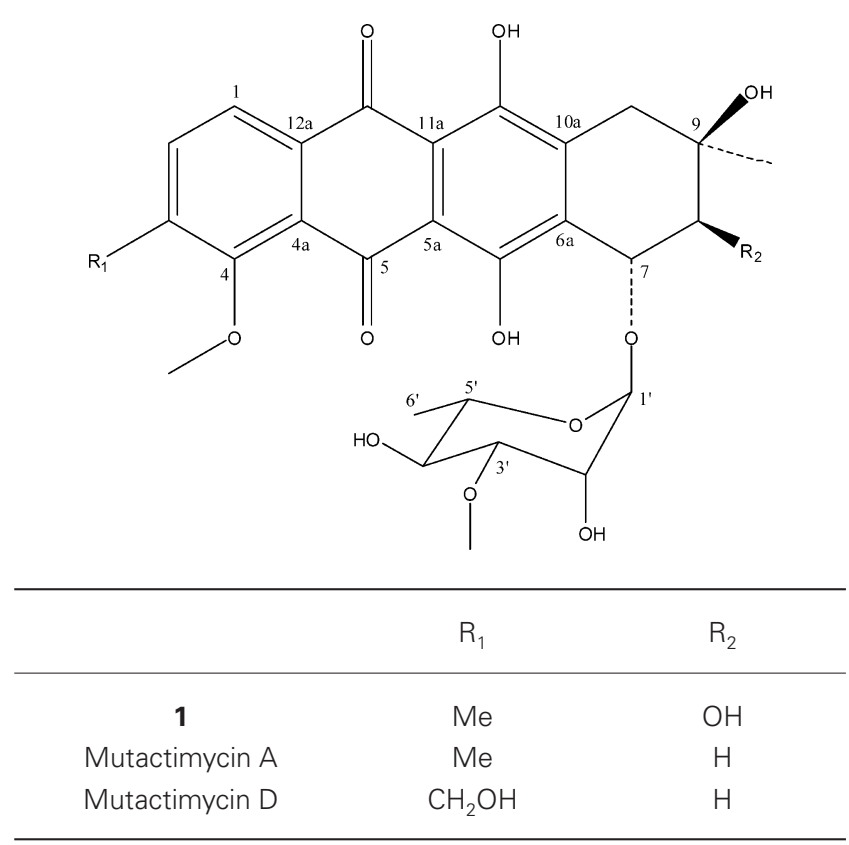

Fig. 1 Structure of mutactimycin E (1).

the compound was related to the mutactimycins [2 5], and possibly was identical to the known metabolite mutactimycin D [6]. However, closer examination of the data suggested $\mathbf{1}$ was a new member of this class of anthracyclines. HRMS analysis of $\mathbf{1}$ provided a molecular formula of $\mathrm{C}_{28} \mathrm{H}_{32} \mathrm{O}_{12}$ based on an ion at $\mathrm{m} / z$ 583.1791 (calcd. 583.1802). A fragment in the LC/MS at $\mathrm{m} / \mathrm{z} 401$ corresponded to the loss of the sugar moiety. Analysis of the COSY spectrum revealed correlations between the five sugar protons. The observation of the coupling constants (Table 1) indicated that the sugar was a mannopyranose. An HMBC correlation was observed between a methyl group at $\delta 3.26$ (H-3-O-Me) and $\mathrm{H}^{-} 3^{\prime}$ on the sugar thus establishing the position of the methoxy group. Additional examination of the NMR data and comparison with literature values allowed us to identify the sugar moiety as a 6-deoxy-3-O-methyl- $\alpha$-mannopyranoside [3, 4]. An HMBC correlation was observed between the anomeric proton at $\delta 5.19\left(\mathrm{H}-1^{\prime}\right)$ and a carbon at $\delta 74.9$ (C-7) (Fig. 2) which indicated the sugar was attached at the C-7 position. Although the molecular weight and UV matched well with mutactimycin $\mathrm{D}$, the absence of an NMR resonance consistent with a $\mathrm{CH}_{2} \mathrm{OH}$ group, as expected for mutactimycin D (Fig. 1), confirmed that the structure of $\mathbf{1}$ was different. Furthermore, an HMBC correlation was seen between the methyl group at $\delta 1.32$ (C-9-Me) and a carbon at $\delta 73.0$ (C-8). This carbon had a corresponding proton signal in the HSQC spectrum which appeared as a doublet
Table $1{ }^{1} \mathrm{H}$ - and ${ }^{13} \mathrm{C}-\mathrm{NMR}$ Data for mutactimycin $\mathrm{E}(\mathbf{1})$ in DMSO- $d_{6}\left(25^{\circ} \mathrm{C}\right)$

\begin{tabular}{|c|c|c|}
\hline Position & $\delta_{\mathrm{H}}$ (mult., $J$ in $\mathrm{Hz}$ ) & $\delta_{\mathrm{C}}$ \\
\hline 1 & $7.98(d, 7.8)$ & 122.6 \\
\hline 2 & $7.78(d, 7.9)$ & 137.0 \\
\hline 3 & & 141.4 \\
\hline 4 & & 159.0 \\
\hline $4 a$ & & 125.0 \\
\hline 5 & & 186.5 \\
\hline $5 a$ & & $110.0^{\mathrm{a}}$ \\
\hline 6 & & 157.8 \\
\hline $6 a$ & & 135.7 \\
\hline 7 & $4.90(d, 3.8)$ & 74.9 \\
\hline 8 & $3.67(d, 4.1)$ & 73.0 \\
\hline 9 & & 70.1 \\
\hline \multirow[t]{2}{*}{10} & $2.63(\mathrm{~d}, 18.2)$ & 33.8 \\
\hline & $2.77(d, 18.1)$ & \\
\hline $10 a$ & & 137.7 \\
\hline 11 & & 155.0 \\
\hline $11 a$ & & $110.7^{a}$ \\
\hline 12 & & 185.7 \\
\hline $12 a$ & & 133.1 \\
\hline 3-Me & 2.37 (s) & 16.3 \\
\hline 9-Me & $1.32(\mathrm{~s})$ & 26.6 \\
\hline 4-O-Me & 3.82 (s) & 60.7 \\
\hline $1^{\prime}$ & 5.19 (br s) & 103.7 \\
\hline $2^{\prime}$ & $3.97(\mathrm{~m})$ & 66.3 \\
\hline $3^{\prime}$ & $3.29(\mathrm{dd}, 9.3,3.3)$ & 80.2 \\
\hline $4^{\prime}$ & $3.31(\mathrm{dd}, 9.3,9.3)$ & 70.7 \\
\hline $5^{\prime}$ & $3.80(\mathrm{dq}, 9.2,6.2)$ & 69.2 \\
\hline $6^{\prime}$ & $1.19(d, 6.2)$ & 17.9 \\
\hline 3'-O-Me & 3.26 (s) & 56.1 \\
\hline $6-\mathrm{OH}$ & $13.26(\mathrm{br} \mathrm{s})$ & \\
\hline $8-\mathrm{OH}$ & 4.58 (br s) & \\
\hline $9-\mathrm{OH}$ & 4.86 (br s) & \\
\hline $11-\mathrm{OH}$ & 14.20 (br s) & \\
\hline $2^{\prime}-\mathrm{OH}$ & $4.81(d, 4.1)$ & \\
\hline $4^{\prime}-\mathrm{OH}$ & 4.75 (br s) & \\
\hline
\end{tabular}

${ }^{a}$ Assignments may be interchanged.

at $\delta 3.67(\mathrm{H}-8)$. HMBC correlations from the latter to $\delta$ 135.7 (C-6a) and $\delta 70.1$ (C-9) and a COSY correlation to a doublet at $\delta 4.90(\mathrm{H}-7)$ confirm the presence of a hydroxyl group at $\mathrm{C}-8$. NMR data for the remaining aglycone resonances were consistent with those of other mutactimycins [3, 4]. The stereochemistry at C-7 and C-9 were established as shown based on comparison with literature values [4]. An NOE experiment revealed the relative stereochemistry at $\mathrm{C}-8$ via a correlation between $\mathrm{H}$ - 


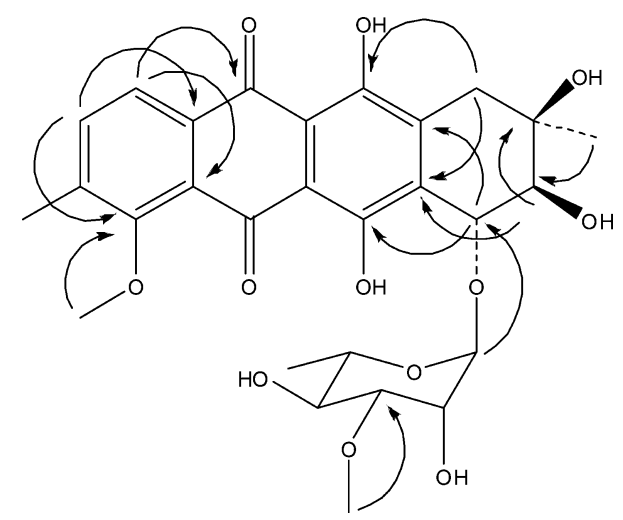

Fig. 2 Key HMBC correlations of 1.

Table 2 Physico-chemical properties of $\mathbf{1}$

\begin{tabular}{|c|c|}
\hline Appearance & Orange crystals \\
\hline Molecular weight & 560 \\
\hline Chemical formula & $\mathrm{C}_{28} \mathrm{H}_{32} \mathrm{O}_{12}$ \\
\hline HR FTICR-MS [M+Na] ${ }^{+}$ & Found 583.1791 \\
\hline$(\mathrm{m} / \mathrm{z})$ & Calcd 583.1802 \\
\hline UV-VIS $\lambda_{\max }\left(\mathrm{CH}_{3} \mathrm{CN}\right) \mathrm{nm}$ & $\begin{array}{l}212,235,257,295,352,470,491 \\
522\end{array}$ \\
\hline IR $v_{\max }\left(\right.$ film) $\mathrm{cm}^{-1}$ & $\begin{array}{l}3406,2936,1681,1614,1573,1409, \\
1257,1237,1137,1102,1055,1032, \\
819\end{array}$ \\
\hline$[\alpha]_{D}^{22}(c 0.002, \mathrm{MeOH})$ & $+78.5^{\circ}$ \\
\hline
\end{tabular}

8 and the methyl group at C-9. Therefore, the structure of $\mathbf{1}$ was established as mutactimycin $\mathrm{E}$ ( $8-\mathrm{OH}$ mutactimycin A). Its physico-chemical properties are summarized in Table 2 .

1 displayed moderate antimicrobial activity against an internal panel of pathogens, which is in good agreement with the bioactivity reported for other mutactimycins [3, 4]. It is also reported that several other members of this group exhibit antiviral activity [3].

A summary of the bioactivities of $\mathbf{1}$ and antibiotic standards daptomycin [7], linezolid [8], and meropenem [9] against a panel of clinical isolates is shown in Table 3 [10]. 1 does not affect HepG2 cell viability at $128 \mu \mathrm{g} / \mathrm{ml}$, the highest concentration of compound tested. Furthermore, no cytotoxic effect was observed when $\mathbf{1}$ was tested against a normal human dermal fibroblasts (NHDF) cell line.

\section{Experimental}

\section{General Experimental Procedures}

${ }^{1} \mathrm{H}$ - and ${ }^{13} \mathrm{C}-\mathrm{NMR}$ as well as COSY, HSQC, and HMBC spectra were recorded using a Bruker DRX 500 NMR spectrometer in DMSO- $d_{6}$ at $500 \mathrm{MHz}$ for ${ }^{1} \mathrm{H}-$ and $125 \mathrm{MHz}$ for ${ }^{13} \mathrm{C}-\mathrm{NMR}$, respectively. Mass spectrometry was performed on a Sciex API150 EX single quadrupole with an ionspray ionization source operating in positive mode. High resolution mass spectra (HRMS) were gathered on a Bruker APEX III 47e Fourier Transform (Ion Cyclotron Resonance) Mass Spectrometer at the Mass Spectrometry Center, University of Washington, Seattle, Washington. Infrared data were obtained on a Perkin Elmer 1600 series FTIR.

Semi-preparative HPLC was carried out using a Waters 600 pump connected to a Waters 996 diode-array detector and controlled by Waters Empower software. The purification employed a Phenomenex Luna $\mathrm{C}_{18}$ column $(10 \times 250 \mathrm{~mm} ; 5.0 \mu \mathrm{m})$. Silica gel $(230 \sim 400 \mathrm{mesh}, \mathrm{EM}$ Science) was used for column chromatography. Fractions were collected $(\sim 50 \mathrm{ml})$ and subsequently monitored by TLC and spots were visualized under UV light.

\section{Producing Organism and Fermentation}

The Amycolatopsis strain 17128 was isolated from a soil sample collected under a rock near Ruby, Arizona. The culture was isolated by spread-plating on Kuster's agar containing $50 \mu \mathrm{g} / \mathrm{ml}$ each of cycloheximide and nystatin, $10 \mu \mathrm{g} / \mathrm{ml}$ each of nalidixic acid and novobiocin and incubating in the dark at $28^{\circ} \mathrm{C}$ for 10 days. Observed colonies were transferred to and maintained on starchcasein agar plates.

The fermentation procedure was a two-step process in which a suspension of spores and mycelium was inoculated into $250-\mathrm{ml}$ flasks containing $25 \mathrm{ml}$ of a nutrient seed medium having the following composition per liter: $20 \mathrm{~g}$ D-glucose, $15 \mathrm{~g}$ pharmamedia, $5.0 \mathrm{~g}$ yeast extract, $4.0 \mathrm{~g}$ $\mathrm{CaCO}_{3}, 3.0 \mathrm{~g}\left(\mathrm{NH}_{4}\right)_{2}\left(\mathrm{SO}_{4}\right)$, and $0.03 \mathrm{~g} \mathrm{ZnSO}_{4} \cdot 7 \mathrm{H}_{2} \mathrm{O}$, adjusted to $\mathrm{pH} 6.5$ prior to autoclaving. After inoculation, the flasks were incubated on a rotary shaker at $250 \mathrm{rpm}\left(2^{\prime \prime}\right.$ throw) and $28^{\circ} \mathrm{C}$ for 2 days. $1.0 \mathrm{ml}$ aliquots of the seed culture were then used to inoculate one hundred $250-\mathrm{ml}$ flasks containing $30 \mathrm{ml}$ of a production medium with the following composition per liter: $20 \mathrm{~g}$ glycerol, $20 \mathrm{~g}$ dextrin, $10 \mathrm{~g}$ soytone, $3.0 \mathrm{~g}$ yeast extract, $2.0 \mathrm{~g}\left(\mathrm{NH}_{4}\right)_{2}\left(\mathrm{SO}_{4}\right)$, and $2.0 \mathrm{~g} \mathrm{CaCO}_{3}$, adjusted to $\mathrm{pH} 7.0$ prior to autoclaving. Following inoculation, the production flasks were incubated on a rotary shaker at $250 \mathrm{rpm}$ and $28^{\circ} \mathrm{C}$ for 7 days. The fermentation flasks were then harvested, and the 
fermentation mixture from each flask was pooled into a single vessel ( $\sim 3$ liters) for extraction with EtOAc.

\section{Extraction and Isolation}

Cultures were harvested by extracting with an equal volume of EtOAc. The organic layer was dried over $\mathrm{Na}_{2} \mathrm{SO}_{4}$ and evaporated to give a dark red solid $(1.0 \mathrm{~g})$. A portion of this $(800 \mathrm{mg}$ ) was dissolved in $200 \mathrm{ml}$ of $\mathrm{MeOH}$ and washed with hexane $(3 \times 200 \mathrm{ml})$. The $\mathrm{MeOH}$ soluble portion $(600 \mathrm{mg})$ was fractionated over a silica gel column (50 g) using a solvent system of $\mathrm{CHCl}_{3}$ and $\mathrm{MeOH}(3: 1)$. Fractions 2 9 contained the desired product and were combined to yield $300 \mathrm{mg}$. This material was dissolved in $\mathrm{CHCl}_{3}(\sim 5.0 \mathrm{ml})$ which gave a cloudy solution. $\mathrm{MeOH}$ was added dropwise until the solution became clear. After 3 hours at $-20^{\circ} \mathrm{C}$, a precipitate formed. The latter was recovered and rinsed with hexane to give $80 \mathrm{mg}$ of a dark red solid. The compound was further purified by reversedphase HPLC using a gradient solvent system of water and $\mathrm{CH}_{3} \mathrm{CN}$ each containing $0.05 \%$ TFA $(95: 5$ to $0: 100$ in 15 minutes; flow $5.0 \mathrm{ml} / \mathrm{minute})$ to yield $40 \mathrm{mg}$ of $\mathbf{1}$.

\section{Antibacterial Assays}

The agents tested were the natural product-derived antibiotic 1, daptomycin (DAP), meropenem (MER) and linezolid (LNZ) (Table 3) and vancomycin (data not shown). Organisms used in this study included strains from the ATCC collection and clinical isolates. MICs were determined using the microdilution method described by CLSI [10].

\section{Cell Culture}

Human hepatocellular carcinoma HepG2 and NHDF cell lines were purchased from ATCC and Lonza, respectively. The HepG2 cell line was maintained in MEM (minimal essential medium) with $10 \%$ heat-inactivated FBS (fetal bovine serum) (Invitrogen), $0.10 \mathrm{mM}$ non-essential amino acids solution (Invitrogen) and $1.0 \mathrm{mM}$ sodium pyruvate (Invitrogen) in a $5 \% \mathrm{CO}_{2}, 37^{\circ} \mathrm{C}$ humidified atmosphere. The NHDF cell line was maintained at no more than 16

Table 3 Bioactivities of $\mathbf{1}$ and selected standards against a panel of clinical isolates

\begin{tabular}{|c|c|c|c|c|c|}
\hline \multirow{2}{*}{ ORGANISM } & \multicolumn{5}{|c|}{$\mathrm{MIC}(\mu \mathrm{g} / \mathrm{ml})$} \\
\hline & PHENOTYPE & 1 & DAP & $L_{N} Z^{b}$ & $\mathrm{MER}^{\mathrm{C}}$ \\
\hline Staphylococcus aureus 100 & $M_{S S A}^{d}$ & 16 & 1 & 4 & 0.25 \\
\hline Staphylococcus aureus 1137 & $\mathrm{MRSA}^{\mathrm{e}}$ & 8 & 1 & 4 & $>4$ \\
\hline Staphylococcus aureus 2012 & VISA $^{f}$ & 8 & 8 & 1 & $>4$ \\
\hline Staphylococcus aureus 1725 & $\operatorname{LRSA}^{g}$ & 16 & 1 & 4 & 0.25 \\
\hline Staphylococcus aureus 6538 & MSSA & 1 & ND & 2 & ND \\
\hline Staphylococcus aureus 43300 & MDRSA $^{\mathrm{h}}$ & 8 & ND & 0.5 & ND \\
\hline Streptococcus pneumoniae 975 & PSSPi & 2 & 0.25 & 1 & 0.015 \\
\hline Streptococcus pneumoniae 940 & PRSP & 1 & 0.25 & 0.25 & 1 \\
\hline Streptococcus pneumoniae 376 & Quin- $R^{k}$ & 2 & 0.25 & 1 & 0.015 \\
\hline Enterococcus faecium & VRE & 8 & ND & 1 & ND \\
\hline Haemophilus influenzae 1742 & ampR' & $>64$ & $>64$ & 8 & 0.06 \\
\hline Haemophilius parainfluenzae 2319 & & $>64$ & $>64$ & 16 & 0.03 \\
\hline Escherichia coli 102 & QC strain & $>64$ & $>64$ & $>64$ & 0.03 \\
\hline Escherichia coli 2269 & ESBL ${ }^{m}$-prod & $>64$ & $>64$ & $>64$ & 0.03 \\
\hline Escherichia coli 1411 & & $>64$ & ND & $>64$ & ND \\
\hline Klebsiella pneumoniae 2239 & & $>64$ & $>64$ & $>64$ & 0.06 \\
\hline Klebsiella pneumoniae 2262 & $\mathrm{ampC}, \mathrm{MDR}^{\mathrm{n}}$ & $>64$ & $>64$ & $>64$ & $>64$ \\
\hline Moraxella catarrhalis 557 & & 8 & 16 & 4 & $\leq 0.004$ \\
\hline Serratia marcescens 1635 & & $>64$ & $>64$ & $>64$ & 0.06 \\
\hline Pseudomonas aeruginosa 1473 & & $>64$ & $>64$ & $>64$ & 4 \\
\hline
\end{tabular}

${ }^{a}$ Daptomycin, ${ }^{b}$ Linezolid, ${ }^{c}$ Meropenem, ${ }^{d}$ Methicillin-susceptible Staphylococcus aureus, ${ }^{e}$ Methicillin-resistant Staphylococcus aureus, ${ }^{\dagger}$ Vancomycinintermediate Staphylococcus aureus, ${ }^{g}$ Linezolid-resistant methicillin-resistant Staphylococcus aureus, ${ }^{\mathrm{h}}$ Multi-drug resistant Staphylococcus aureus,

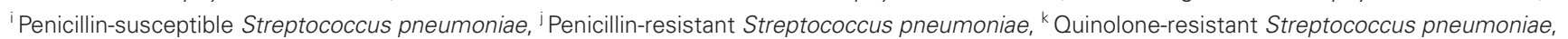
'Ampicillin-resistant, ${ }^{m}$ Extended spectrum beta-lactamase, ${ }^{n}$ ampC beta-lactamase, multidrug-resistant. 
cell passages in a $5 \% \mathrm{CO}_{2}, 37^{\circ} \mathrm{C}$ humidified atmosphere using FGM-2BulletKit ${ }^{\circledR}$ (Lonza) based on Lonza's recommendations.

\section{Cytotoxicity Assay}

HepG2 and NHDF cells were seeded and cultured in microtiter plates 24 hours prior to the addition of test samples. Compounds were resuspended in DMSO and diluted in assay media for a concentration testing range of 0.6 to $128 \mu \mathrm{g} / \mathrm{ml}$ at a final DMSO concentration of $1.0 \%$. After incubation with the test samples for 48 hours, cell viability was assayed by measuring changes in cellular ATP levels using the CellTiter Glo ${ }^{\circledR}$ Luminescent kit from Promega following the manufacturer's instructions $[12,13]$. Cytotoxicity was calculated as a percentage of the DMSO control.

Acknowledgments We thank Dr. Ross Lawrence (University of Washington) for HRMS measurements and Maria Yusupova for her help with the isolation of $\mathbf{1}$.

\section{References}

1. Dictionary of Natural Products, Chapman \& Hall/CRC, Version 16:2, December 2007

2. Jin WZ, Cheng J, Zhang YB, Li HL, Tao PZ. Isolation and structure determination of mutactimycin A, a new anthracycline antibiotic. Kangshengsu 15: 399-406 (1990)
3. Mikami Y, Yazawa K, Ohashi S, Maeda A, Akao M. SO75R1, a new mutactimycin derivative produced by Nocardia brasiliensis. J Antibiot 45: 995-997 (1992)

4. Speitling M, Nattewan P, Yazawa K, Mikami Y, GruenWollny I, Ritzau M, Laatsch H, Graefe U. Demethyl mutactimycin, new anthracycline antibiotics from Nocardia and Streptomyces strains. J Antibiot 51: 693-698 (1998)

5. Zitouni A, Mathieu F, Coppel Y, Pont F, Sabau N, Lebrihi A. Mutactimycin PR, a New Anthracycline Antibiotic from Saccharothrix sp. SA 103. J Antibiot 57: 373-378 (2004)

6. Zhang Y, Jin W. Isolation and structure determination of minor components of mutactimycins, a group of new anthracycline antibiotics. Kangshengsu 16: 157-164 (1991)

7. Alder JD. Daptomycin, a new drug class for the treatment of Gram-positive infections. Drugs Today 41: 81-90 (2005)

8. Ford CW, Zurenko GE, Barbachyn MR. The discovery of linezolid, the first oxazolidinone antibacterial agent. Cur Drug Targets 1: 19-36 (2001)

9. Sunagawa M, Matsumura H, Inoue T, Fukusawa M, Kato M. A novel carbapenem antibiotic, SM-7338 structure-activity relationships. J Antibiot 43: 519-532 (1990)

10. Data were generated in house and by Micromyx, LLC (Kalamazoo, MI)

11. Clinical Laboratory Standards (CLSI/NCCLS) Approved Standard M7-A7 (2006)

12. Mueller H, Kassack MU, Wiese M. Comparison of the usefulness of the MTT, ATP, and calcein assays to predict the potency of cytotoxic agents in various human cancer cell lines. J Biomol Screen 9(6): 506-515 (2004)

13. Moravec R, Beck M, Hannah R. Promega Cell Notes 2: 13-16 (2001) 